\title{
Serological markers of inflammatory bowel disease
}

\author{
Andrea Tešija Kuna \\ University Department of Chemistry, Medical School University Hospital Sestre Milosrdnice, Zagreb, Croatia \\ Corresponding author: andrea.kuna@gmail.com
}

\begin{abstract}
Inflammatory bowel disease (IBD) is a heterogeneous group of chronic inflammatory disorders of the gastrointestinal tract with two main distinguishable entities, Crohn's disease (CD) and ulcerative colitis (UC). IBD-unclassified (IBD-U) is a diagnosis that covers the "grey" zone of diagnostic uncertainty between UC and CD. Current diagnosis of IBD relies on the clinical, endoscopic, radiological, histological and biochemical features, but this approach has shortcomings especially in cases of overlapping symptoms of CD and UC. The need for a diagnostic tool that would improve the conventional methods in IBD diagnosis directed the search towards potential immunological markers, since an aberrant immune response against microbial or endogenous antigens in a genetically susceptible host seems to be implicated in IBD pathogenesis. The spectrum of antibodies to different microbial antigens and autoantibodies associated with IBD is rapidly expanding. Most of these antibodies are associated with CD like anti-glycan antibodies: anti-Saccharomices cerevisiae (ASCA) and the recently described anti-laminaribioside (ALCA), anti-chitobioside (ACCA), anti-mannobioside (AMCA), anti-laminarin (anti-L) and anti-chitin (anti-C) antibodies; in addition to other antibodies that target microbial antigens: anti-outer membrane porin ( (anti-OmpC), anti-Cbir1 flagellin and anti-12 antibody. Also, autoantibodies targeting the exocrine pancreas (PAB) were shown to be highly specific for CD. In contrast, UC has been associated with anti-neutrophil cytoplasmic autoantibodies (pANCA) and antibodies against goblet cells (GAB). Current evidence suggests that serologic panels of multiple antibodies are useful in differential diagnosis of CD versus UC and can be a valuable aid in stratifying patients according to disease phenotype and risk of complications.
\end{abstract}

Key words: inflammatory bowel disease; colitis, ulcerative; Crohn disease; serological tests

\section{Introduction}

The term IBD refers to a chronic and relapsing inflammatory disorder of the gastrointestinal tract (GIT) accompanied by abdominal pain, rectal bleeding and malabsorption. It comprises two major entities, ulcerative colitis (UC) and Crohn's disease (CD). Despite sharing similar clinical features, these diseases have significant clinical, endoscopic and histopathological differences (Table 1) (1-4).

Typically, IBD manifests between adolescence and the third decade of life, with approximately $10 \%$ of cases in individuals younger than 18 years (5). IBD diagnosis is based upon the coevaluation of clinical findings, endoscopic, radiological, histological and laboratory investigations with the main goal of excluding other conditions with similar presentations and defining the extent and severity of inflammation. In the majority of cases, endoscopic findings and histological examination of tissue biopsies provides a specific diagnosis of UC or CD (3,6-8). However, despite all available diagnostic methods, approximately 5 to $15 \%$ of patients with IBD affecting the colon are unclassifiable, as they present features of both conditions. Such patients are diagnosed with indeterminate colitis (IC) or IBD unclassified (IBDU), which is considered to be a temporary diagnosis since about $80 \%$ of these pa- 
TABLE 1. The key features of Crohn's disease and ulcerative colitis.

\begin{tabular}{lcc}
\hline Feature & Crohn's disease & Ulcerative colitis \\
\hline Clinical features & & Very common \\
$\begin{array}{l}\text { Diarrhea } \\
\text { Rectal bleeding }\end{array}$ & Fairly common \\
\hline Sites of involevment & Fairly common & Very comon \\
lleum and colon (ileocolonic region) & $50 \%$ of patients & Never \\
lleum & $30 \%$ of patients & Never \\
Colon & $20 \%$ of patients & Never \\
Upper parts of GIT & Infrequent & Continous lesions, pseudopolyps \\
\hline Endoscopic findings & Discontinuous lesions, cobblestoning, \\
\hline Histologic findings & aphthous and linear ulcerations, strictures & Mucosal/submucosal inflammation \\
\hline
\end{tabular}

tients will eventually be diagnosed with either UC or $\mathrm{CD}(2,9,10)$.

The growing body of evidence suggests that IBD evolved as a result of inappropriate and ongoing activation of the mucosal immune system driven by the commensal luminal microflora in a genetically susceptible host $(2,4,11-14)$. The triggering factor for disturbance of the tightly regulated balance between immune tolerance and defensive inflammatory response to intestinal microbiota is yet to be discovered. The serological immune response in IBD patients, which includes antibodies against the yeast Saccharomyces cerevisiae (ASCA), Escherichia coli outer membrane porin C (Omp-C), flagelin (cBir1) and Pseudomonas fluorescens - associated sequence I-2 (I2), suggests that commensal flora or a dietary antigen is the triggering factor. On the other hand, the autoimmune concept has its base in the autoimmune extraintestinal manifestations of IBD (inflammation of the skin, eyes and joints), successful immunosupressive therapy and a variety of autoantibodies including antineutrophil cytoplasmic antibodies (ANCA), antibodies against exocrine pancreas (PAB) or intestinal goblet cells (GAB) (15-17).

The objective of this review is to give an overview of the current knowledge of the serological markers in IBD with regard to their use in differentiating
IBD from other conditions with similar presentation, in differentiating UC from $C D$, in disease stratification and prediction and, finally, their response to therapeutic interventions in IBD.

\section{Serologic markers of IBD}

Generally, antibodies related to IBD encompasses two main groups: antibodies targeting microbial antigens and autoantibodies (Table 2.).

TABLE 2. Serological markers of IBD.

\begin{tabular}{cc}
\hline Antibodies to microbial antigens & Autoantibodies \\
\hline Anti-glycan antibodies (ASCA, & pANCA \\
ACCA, ALCA, AMCA, Anti-L, Anti-C) & \\
Anti-OmpC & PAB \\
Anti-I2 & GAB \\
Anti-Cbir1 & \\
\hline
\end{tabular}

ASCA - Anti-Saccharomyces cerevisiae antibodies; ACCA antichitobioside carbohydrate antibodies; ALCA - antilaminaribioside carbohydrate antibodies; AMCA - anti-mannobioside carbohydrate antibodes; Anti-L - anti-laminarin antibodies; Anti-C - anti-chitin antibodies; Anti-OmpC - antibody to outer membrane porin C; Anti-12 - antibody to Pseudomonas fluorescens - associated sequence 12; Anti-Cbir1 - antibody to bacterial flagellin; pANCA anti-neutrophil cytoplasmic antibodies; PAB - antibodies against exocrine pancreas; GAB - antibodies to goblet cells. 


\section{Anti-glycan antibodies}

These antibodies targets cell wall carbohydrate epitopes found in microbiota such as yeasts and bacteria $(18,19)$. The most prominent member of this group of antibodies are anti-Saccharomyces cerevisiae antibodies (ASCA). The major antigen targeted with ASCA antibodies is the $200 \mathrm{kDa}$ phosphopeptidomannan (PPM), a cell wall mannan of the common baker's or brewer's yeast Saccharomyces cerevisiae. The greatest discrimination among patients with Crohn's disease, ulcerative colitis, and controls was obtained with the Su1 strain of S. cerevisiae used in beer brewing and mannotetraose was identified as the most important polysaccharide epitope within PPM $(16,20)$. Regarding the widespread distribution of oligomannosides, three theories have been presented in an attempt to explain the mannose-induced immunological response. The first theory assumed that ASCA antibodies originate from immunization by dietary yeasts or yeasts that colonize the digestive tract, as a consequence of increased exposure of yeast antigens to immune reactive cells due to increased intestinal permeability (20-23). The second theory considers the epitopes shared by other microorganisms (Mycobacterium species), and the third presupposes structural homologies between S. cerevisiae oligomannosides and oligomannosides expressed on human glycoconjugates as autoantigens or neoautoantigens $(20,24)$. ASCA was shown to have a high specificity for $C D$, and both $\lg A$ and $\lg G$ antibodies are formed. Methods used for the detection of these antibodies are indirect immunofluorescence (IIF) using smears of Saccharomyces cerevisiae or standardized enzyme linked immunosorbent (ELISA) assays with an antigen derived from disrupted or boiled $S$. cerevisiae and phosphopeptidomannan purified from the cell wall (gASCA assay) coated on microtiter plates (25-30).

In an attempt to identify novel antibodies associated with inflammatory bowel disease, Dotan et al. (18) profiled sugar-binding antibodies from the serum of patients with diagnosed CD or UC using glycan array technology and ELISA. The newly identified antibodies were antilaminaribioside carbohydrate lgG antibodies (ALCA), antichitobioside carbohydrate IgA antibodies (ACCA) and anti-man- nobioside carbohydrate IgG antibodes (AMCA) $(18,31,32)$. Laminaribioside is a building block of the glucose-based glycan laminarin, while chitobioside is a building block of the N-acetyl-glucosamine-based glycan chitin. Both laminaribioside and chitobioside, as well as mannose and mannan, are components of the cell walls of microorganisms such as bacteria, fungi and yeast and are capable of stimulating the immune system, specifically innate immunity (33). The most recently discovered members of the anti-glycan family of antibodies in IBD were anti-laminarin (anti-L) IgA antibodies and anti-chitin (anti-C) IgA antibodies (34). Similarly to ASCA, these antibodies have proven to be specific for $C D$, though with significantly lower sensitivity.

\section{Antibody to outer membrane porin (anti-OmpC)}

$\mathrm{OmpC}$ is an outer membrane porin $\mathrm{C}$ isolated from Escherichia coli. Originally, this protein was identified as a pANCA cross-reactive antigen using the library of colonic bacteria (35). The ELISA assay demonstrated an excessive secretion of IgA antiOmpC antibodies in CD patients $(36,37)$.

\section{Antibody to Pseudomonas fluorescens - asso- ciated sequence 12 (anti-I2)}

In 2000, the novel DNA sequence (I2) with homology to the ptxR and tetR bacterial transcription factor family was isolated from CD colonic lesional mucosa, suggesting that the microorganism expressing the 12 gene product may be related to $C D$ pathogenesis (38). This bacterial sequence has been shown to derive from Pseudomonas fluorescens (39). An ELISA assay showed frequent immunoglobulin A seroreactivity in CD as opposed to UC or other inflammatory enteric diseases and healthy individuals $(37,38)$.

\section{Antibody to bacterial flagellin CBir1 (anti-CBir1)}

Among bacterial antigens, flagellin is an interesting candidate to play a role in mucosal immune responses because it is a common bacterial antigen present on most motile bacteria in the gut and is highly antigenic. Multiple strains of colitic mice had elevated serum anti-flagellin IgG2a responses, 
and flagellin CBir1 has been identified as an immunodominant colitogenic antigen. In line with this, it has high anti-CBir1 IgG reactivity in human CD patient sera, as detected with the ELISA assay, and only minor reactivity in the sera of patients with UC or other inflammatory GIT diseases. CBir1 flagellin is most closely related to the flagellins of bacteria in the genera Butyrivibrio, Rosburia, Thermotoga, and Clostridium and fall within the Clostridium subphylum XIVa cluster of Gram-positive bacteria (40).

\section{Anti-neutrophil cytoplasmic antibodies (ANCA)}

ANCAs are classically associated with small-vessel systemic vasculitis such as Wegener granulomatosis, Churg-Strauss syndrome, microscopic polyangiitis and its renal-limited variant (pauci-immune necrotizing and crescentic glomerulonephritis), where their measurement is used in the purposes of diagnosis, prognosis and in monitoring of inflammatory activity (41). In vasculitis, this heterogenous family of antibodies targets different proteins, mainly located in the azurophilic granules of neutrophils and in lysosomes of monocytes. According to the International Consensus Statement (41), ANCAs are screened by indirect immunofluorescence (IIF) on normal peripheral blood neutrophils where two main types of fluorescence pattern are obtained: cytoplasmic granular with accentuation between nuclear lobes (CANCA) and fine homogenous, diffuse rim-like staining of the perinuclear cytoplasm (or rim-accentuated fluorescence of the nuclei) designated as the pANCA pattern. The major ANCA antigen targets in inflammatory vasculitides are proteinase-3, mainly displaying CANCA pattern and myeloperoxidase associated with the pANCA pattern (41-43).

The distinct subset of ANCA associated with UC was first reported in $1990(44,45)$. The pattern of staining on IIF exhibited broad inhomogeneous rim-like staining of the nuclear periphery, different from classical pANCA and was designated as atypical p-ANCA. Various target antigens of atypical pANCA have been intensively studied in IBD patients. These studies included proteins located in the granules of the neutrophils and monocytes such as: serine proteases cathepsin $\mathrm{G}$ and elastase, hydrolase $\beta$-glucuronidase, iron-binding protein lactoferrin and the natural antibiotic bactericidal permeability increasing protein (BPI); cytoplasmic proteins such as $\alpha$-enolase and catalase; proteins distributed in the cytoplasm and nuclei of eukaryotic cells: high-mobility group of non-histone chromosomal proteins (HMG-1 and HMG-2), and finally proteins located in the nuclei, such as histone $\mathrm{H} 1 \quad(25,27)$. Overall, most studies supported the conclusion that IBD-associated ANCA specific antigens are not located within neutrophil granulas but rather within the nuclei. The immunoelectron microscopy finding of UC-associated PANCA reactivity localized over chromatin concentrated toward the periphery of the nuclei supports this thesis (46). However, UC sera did not react with double-stranded DNA. Vidrich et al. (47) demonstrated the loss of the UC-related pANCA staining pattern after digestion of substrate cells with DNAse, suggesting that the epitope recognized by this subset of antibodies is a protein-DNA complex or that the presence of intact DNA is necessary to maintain the integrity of the epitope. It is likely that the target antigen for UC-related atypical pANCA is a complex conformational epitope which comprises the previously reported nuclear proteins histone H1, HMG-1 and HMG-2. Since the target antigen for UC-associated PANCA is yet unrecognized, sensitive and specific solid-phase methods cannot be developed, and therefore IIF on normal peripheral blood neutrophils is still the most commonly employed method in use. Detection of DNase I - sensitive PANCA antibody is more specific for UC in differentiation from similar pANCA patterns in autoimmune liver diseases. Recently, lactoferrin was suggested as a major pANCA target in UC but it has to be bound to DNA to present epitope relevant for the reaction with the autoantibodies. Use of the lactoferrin reconstituted (LFR) granulocytes (granulocytes stripped of pANCA targets and then reconstituted with human lactoferrin) as a substrate in addition to standard ethanol-fixed granulocytes raised the sensitivity of the IIF assay from $71.8 \%$ to $87.2 \%$ (48).

\section{Antibodies against exocrine pancreas (PAB)}

These antibodies were first described in 1987 by Stöcker et al. (49) who tested sera of patients with 
CD and UC for autoantibodies by the IIF method using 19 different human tissues as antigenic substrates. They demonstrated that autoantibodies against exocrine pancreas (PAB) were found almost exclusively in $C D$ patients (although with rather low sensitivity) and suggested that this specific autoantigen is a component of normal pancreatic juice. In the IIF assay on sections of human or primate pancreatic tissue, PAB antibodies stain different structures of the exocrine pancreas and are divided into two subtypes accordingly: subtype I with a typical, extracellular, drop-like staining pattern in the acinar lumen of pancreatic tissue sections, and subtype II with speckled staining of the cytoplasm of pancreatic acinar cells (50). Recently, the major zymogen granule membrane glycoprotein (GP2), a glycosylphosphatidylinositol (GPI)-anchored protein of the pancreatic acinar cells was identified as the autoantigen of PAB in $C D$ (51). Upon hormonal or neuronal stimulation of the pancreas, GP2 is transported to the apical compartment of acinar cells, from which it is released, together with zymogens, into the pancreatic duct. The two obtained fluorescence patterns of PAB on pancreatic tissue are consistent with the localization of GP2. In addition to pancreatic acinar cells, $M$ cell-specific expression of GP2 in humans and mice was also seen among the intestinal epithelium $(52,53)$ The characteristic of the M-cells as specialized epithelial cells of mucosa-associated lymphoid tissues (Peyer's patches) is their role in the transport of antigens from the lumen to the cells of the immune system (54). It was found that the GP2 expressed on M cells serves as an uptake receptor for a subset of commensal and pathogenic bacteria (53). Bearing in mind that Peyers patches are abundant in the distal part of the ileum, the predominant site of inflammatory onset in CD, Roggenbuck et al. (51) demonstrated GP2 expression at mRNA and protein levels in colon biopsies from patients with CD at a significantly higher level than in UC colon biopsies. This observation supports the hypothesis of a direct involvement of anti-GP2 in CD pathophysiology, rather than being merely an epiphenomenon as an antibody targeting non-intestinal antigen.

\section{Antibodies to goblet cells (GAB)}

Intestinal epithelial cells represent a physical barrier against the excessive entry of bacteria and other antigens from the intestinal lumen into the circulation. Goblet cells, as specialized intestinal epithelial cells, regulate the production of mucus and factors that contribute to epithelial repair and regulation of inflammation (4). GAB have been detected primarily in adult UC patients with prevalence varying from $15 \%$ to $46.6 \%$ while in CD patients observed prevalence of $G A B$ showed even wider range from $1.4 \%$ to $33 \%(15,49,55,56)$. Obtained differences in $G A B$ prevalence are likely attributed to methodological differences, such as the use of different origin of antigenic substrate for IIF: human or monkey intestinal tissue, rarely rat jejunum or human colonic cancer cell line HT29-18-N2, which differentiates into intestinal goblet cells. Tissue substrates are associated with problematic reproducibility due to the natural fluctuations of tissue quality. The next sources of variability in the obtained results lie in the evaluation of fluorescence patterns on IIF. Beside the IIF test, the ELISA assay using the HT29-18-N2 cell line assay is also in use for GAB detection (55).

\section{Clinical usefulness of serological investigation of IBD}

The main concerns regarding clinical usefulness of serological markers in IBD refers to: a) their efficiency in distinguishing IBD from other diseases with similar clinical presentation and in distinguishing subtypes of IBD (ulcerative colitis from Crohn's disease), b) their prognostic value in stratifying disease phenotypes, and c) monitoring disease activity and reflecting the response to therapeutic intervention.

\section{Serological investigation for IBD diagnostic purposes}

Use of serological markers in distinguishing IBD from other non-IBD gastrointestinal diseases

Currently, diagnosis of IBD is based on a combination of clinical, radiological, endoscopic and histological studies and, in most cases, the diagnosis 
can be made with high certainty. Assessment of the currently known IBD-associated antibodies has not surpassed the diagnostic accuracy of the previously mentioned conventional methods, mainly due to their limited sensitivity (Table 3$)(15,19,26,27$, 29,33,55,56-59).

A positive test result for any individual antibody, even those with highest sensitivity like PANCA or ASCA, only modestly influences the pretest/posttest probability in distinguishing IBD from other GIT disorders with similar clinical presentation, while a negative test result has no clinical value. Although most studies have confirmed the high specificity of IBD-associated antibodies (75-99\%), caution should be taken in considering the control groups of non-IBD GIT disorders that mainly included irritable bowel syndrome, infectious colitis or functional gut disorders (26). Namely, ASCA that was considered as a highly CD-specific antibody was observed in 30\% to even $59 \%$ of patients with celiac disease prior introducing the gluten-free diet. ASCA antibodies were more often of the lgG class and were, unlike the ASCA-IgA, insensitive to gluten withdrawal $(60,61)$. Another highly CD-specific antibody, PAB, showed a frequency of $22.3 \%$ in celiac patients at diagnosis (more often $\lg A$ class), and positivity demonstrated a tendency to be lower in patients on a strict gluten-free diet (56). This observation suggests that the presence of ASCA or PAB may be a marker for increased permeability of the small bowel and autoimmunity instead of a specific IBD (CD) marker.

Therefore, at the present, assessment of serological markers are not suitable for screening for IBD in patients with gastrointestinal symptoms, but rather as assistance in cases of a diagnostic dilemma.

The variation in the prevalence of individual serological markers across studies could be explained by differences in the methods used. For example, PANCA have been determined with standardized IIF on ethanol fixed neutrophils from healthy donors, or with fixed granulocytes ELISA, or using ELISA followed with IIF for ANCA-ELISA positive samples. Some studies were performed with IIF including the step with DNase I digestion of neutrophils. Variation in the sensitivity of pANCA as-

TABLE 3. Prevalence of individual serological markers in patients with IBD, non-IBD GIT disorders and healthy individuals (15,19,26, 27,29,33,55-59).

\begin{tabular}{|c|c|c|c|c|c|}
\hline \multirow{2}{*}{ Antibody } & \multirow{2}{*}{$\begin{array}{l}\text { Immunoglobulin } \\
\text { class }\end{array}$} & \multicolumn{4}{|c|}{ Prevalence (\%) } \\
\hline & & CD & UC & other GIT disorders & Healthy \\
\hline ASCA & $\lg A$ and/or $\lg G$ & $29-71$ & $0-29$ & $0-23(37.9)^{*}$ & $0-16$ \\
\hline ACCA & $\lg A$ & $8-25$ & $5-7$ & $3-20$ & $0.5-12$ \\
\hline ALCA & $\lg G$ & $17.7-27$ & $3-8$ & 9 & 2 \\
\hline AMCA & $\lg G$ & $12-28$ & 7 & 8 & 9 \\
\hline Anti-L & $\lg A$ & $11-26$ & $3-7$ & 23 & $1-10$ \\
\hline Anti-C & $\lg A$ & $10-25$ & $2-10$ & 11 & $2-12$ \\
\hline Anti-OmpC & $\lg A$ & $24-55$ & $2-24$ & $5-11$ & $5-20$ \\
\hline Anti-12 & $\lg A$ & $38-60$ & $2-10$ & 19 & $5-15$ \\
\hline Anti-Cbir1 & $\lg G$ & $50-56$ & $<6$ & 14 & 8 \\
\hline PAB & $\lg A$ and $\lg G$ & $26-39$ & $0-22.7$ & $0-11.5(22.3)^{*}$ & $0-8$ \\
\hline GAB & $\lg A$ and $\lg G$ & $1.4-33$ & $15.4-46.6$ & $0-9.3$ & 0 \\
\hline pANCA & $\lg G$ & $2-38$ & $24-85$ & 8 & $0-8$ \\
\hline
\end{tabular}

* prevalence in active celiac disease. CD - Crohn's disease; UC - ulcerative colitis; ASCA - Anti-Saccharomyces cerevisiae antibodies; ACCA antichitobioside carbohydrate antibodies; ALCA - antilaminaribioside carbohydrate antibodies; AMCA - anti-mannobioside carbohydrate antibodes; Anti-L - anti-laminarin antibodies; Anti-C - anti-chitin antibodies; Anti-OmpC - antibody to outer membrane porin C; Anti-I2 - antibody to Pseudomonas fluorescens - associated sequence 12; Anti-Cbir1 - antibody to bacterial flagellin; PAB - antibodies against exocrine pancreas; GAB - antibodies to goblet cells; pANCA - anti-neutrophil cytoplasmic antibodies. 
says from 0-63\% in UC samples across five different laboratories suggests that these assays obviously do not detect the same spectrum of antigens (28). Also, considerable lack of agreement exists within the same methodology due to differences in antigen preparation and quality, cut-off values based on the receiver operating curve, differences in evaluation of fluorescence patterns for IIF methods, cut-off titer or the origin of the substrate used for IIF.

\section{Distinguishing CD from UC}

The heterogeneity within the IBD group of disorders influences the clinical presentation with overlapping symptoms of CD and UC. In up to $15 \%$ of cases, no differentiation into a particular IBD subtype can be made, giving rise to a diagnosis of IBD-unclassified (IBD-U) or previously known as indetermined colitis (IC). Differentiation into either of the IBD subtypes in the early phase of the disease has an influence on the tailoring of drug therapy. According to retrospective database analysis of 250 children diagnosed with IBD, IBD-U appears to have a higher prevalence among paediatric patients (up to 29.6\%) and is associated with early disease onset and rapidly progresses to pancolitis (62). In the same study, 66.2\% patients maintained their diagnosis of IBD-U after a mean follow-up of 7 years, which favours the hypothesis of some investigators that IBD-U is a unique disease phenotype within the IBD group, with more a extensive disease, more severe clinical course and higher rate of complications. Paediatric IBD patients comprise a particular population in whom non-invasive testing is desirable and who would benefit the most from the early proper therapeutic approach. As the specificity of serological markers exceeds their sensitivity, serological profiles can be useful in the differentiation of IBD subtypes $(62,63)$.

Most of the data pertaining to the usefulness of serological markers in distinguishing $C D$ from UC refer to the ASCA and PANCA antibodies, while fewer data are available for other anti-glycan antibodies, anti-I2, anti-Omp-C, anti-Cbir1, PAB or GAB. Overall, ASCA has the best combined sensitivity and specificity for CD and PANCA for UC. Most other investigated serological markers are specific for $C D$, with the exception of GAB. Table 4. summarizes the data on diagnostic accuracy of individual and combined antibodies in the differential diagnosis of of CD and UC (10,15,26-30,56,64-66).

The general opinion is that combined testing instead of individual antibodies is more useful in obtaining a differential diagnosis of $C D$ versus UC. Profile ASCA+/pANCA- increases specificity and positive predictive value (PPV) for diagnosis of $C D$ comparing to ASCA+ as isolated result. In the same manner, the reverse profile pANCA+/ASCA- was shown to have a higher specificity and PPV for diagnosis of UC than PANCA+ alone (26-30). Profile PANCA-/ASCA- was found to have a strong positive correlation with IBD-U diagnosis. Prospective study of IBD-U patients revealed that half of the patients had pANCA-/ASCA- seroprofile and the vast majority of them did not change the initial diagnosis after 6 years. Therefore, pANCA-/ASCAseems to be the serological marker closely associated with IBD-U as a separate disease entity $(30,63)$.

Recent study assessed the reactivity of seven antiglycan antibodies in a large cohort of 818 IBD patients, including gASCA IgA and $\lg$ (gASCA is an improved ASCA assay based on immobilized purified mannan polysaccharide), ACCA, ALCA, AMCA, anti- $L$ and anti-C (34). Within the $C D$ patient population, 73\% were positive for $\geq 1$ anti-glycan antibody. All anti-glycan markers were specific for $C D$ and were significantly more prevalent in $C D$ than in UC. The most efficient discrimination between $C D$ and UC was achieved by the addition of anti- $L$ and anti-C to gASCA/pANCA panel while adding of anti- $L$ to the same panel improved differentiation of colonic CD from UC.

Diagnostic accuracy for CD versus UC of the gASCA and ALCA antibodies was find out to be similar between adult and paediatric IBD cohorts, while discrepancies were found for AMCA and ACCA. In paediatric population, both serologic markers showed significantly higher specificity, while AMCA showed significantly lower sensitivity compared to adults (33).

The importance of combined testing was pointed out by the finding that about one third of ASCA negative $C D$ patients may be positive for at least 
TABLE 4. Diagnostic accuracy of individual serological markers and their combinations in differential diagnosis of CD and UC (10,15,26$30,56,64-66)$.

\begin{tabular}{|c|c|c|c|c|c|}
\hline Diagnosis & Antibody & Sensitivity (\%) & Specificity (\%) & PPV & NPV \\
\hline \multirow{13}{*}{ CD } & $\mathrm{ASCA}+$ & $37-72$ & $82-100$ & $87-95$ & $36-68$ \\
\hline & pANCA - & 52 & 91 & 85 & 65 \\
\hline & ACCA & $9-21$ & $84-97$ & $78-87$ & $24-52$ \\
\hline & ALCA & $15-26$ & $92-96$ & $78-90$ & $25-53$ \\
\hline & AMCA & $12-28$ & $82-97$ & $65-92$ & $25-52$ \\
\hline & Anti-C & $10-25$ & $90-98$ & $87-88$ & $29-39$ \\
\hline & Anti-L & $18-26$ & $93-97$ & $90-91$ & $30-40$ \\
\hline & Anti-OmpC & $20-55$ & $81-88$ & 83 & 25 \\
\hline & Anti-12 & 42 & 76 & NR & NR \\
\hline & PAB & $22-46$ & $77-100$ & $69-100$ & $48-75$ \\
\hline & ASCA+/pANCA- & $46-64$ & $92-99$ & $86-97$ & $44-82$ \\
\hline & $\mathrm{PAB}+/ \mathrm{ANCA}-$ & $22-42$ & $98-100$ & $87-100$ & $48-74$ \\
\hline & $\mathrm{PAB}+/ \mathrm{ASCA}+/ \mathrm{pANCA}-$ & $16-34$ & $97-100$ & 100 & $66-72$ \\
\hline \multirow{4}{*}{ UC } & PANCA & $50-71$ & $75-98$ & $74-95$ & $49-84$ \\
\hline & pANCA+/ASCA- & $42-58$ & $81-100$ & $93-100$ & 43 \\
\hline & GAB & $12^{*}-46$ & 98 & $75-93$ & $70-74$ \\
\hline & pANCA or GAB+/PAB- & 82 & 98 & 96 & 89 \\
\hline \multicolumn{6}{|c|}{$\begin{array}{l}\text { * in pediatric population. PPV - positive predictive value; NPV - negative predictive value; ASCA - Anti-Saccharomyces cerevisiae } \\
\text { antibodies; pANCA - anti-neutrophil cytoplasmic antibodies; ACCA - antichitobioside carbohydrate antibodies; ALCA - antilaminaribiosid } \\
\text { carbohydrate antibodies; AMCA - anti-mannobioside carbohydrate antibodes; Anti-C - anti-chitin antibodies; Anti-L - anti-laminarin } \\
\text { antibodies, Anti-OmpC - antibody to outer membrane porin C; Anti-I2 - antibody to Pseudomonas fluorescens - associated sequence I2, } \\
\text { PAB - antibodies against exocrine pancreas; GAB - antibodies to goblet cells; NR - not reported. }\end{array}$} \\
\hline
\end{tabular}

one of the previously mentioned anti-glycan antibodies (67).

Similarly, anti-CBir1 were positive in about half of ASCA-negative adult CD patients while the addition of the anti-CBir1 assay to the ASCA, pANCA and anti-OmpC panel halved the number of serologically negative paediatric CD patients $(68,69)$.

PAB was confirmed as a highly specific marker of $C D$ in several studies, but with low sensitivity $(15,29,65)$. Therefore, the use of PAB in combination with pANCA and ASCA was suggested, particularly in the differentiation between isolated colonic CD and UC where the clinical difficulty lies in the differentiation between CD and UC. In another study, authors concluded that PAB detection could be useful only in clinically highly suspected patients without circulating ASCA, since they found $P A B$ positivity in $14 \%$ of $C D$ patients that were neg- ative for ASCA (29). Several studies, however, showed lower specificity of PAB in distinguishing CD from UC both in adult and paediatric patients $(56,63,66)$.

In majority of reports, GAB was confirmed as highly specific serological marker in distinguishing UC from $C D$, but due to the low sensitivity (especially in paediatric population, $12 \%$ ) it is poorly usable in differential diagnosis of IBD subtypes, both in adults and children $(15,56,65,66,70)$.

However, in a recent study by Homsak et al. (15), the combination of positive PANCA or GAB with negative $P A B$ managed to detect the majority of UC patients.

In summary, testing for isolated antibody is of limited value in differential diagnosis of IBD subtypes, while the combined testing of several antibodies (serologic panels) significantly improves specificity 
and PPV for certain IBD subtype. Furthermore, widening panel of antibodies can also improve the sensitivity. However, result of serological testing is not decisive but is an adjunctive tool in patients in whom all other clinical features does not allow a distinction between CD and UC.

\section{Use of serological testing in disease phenotype stratification}

The heterogenic nature of both CD and UC is reflected in the different phenotypes of the disease, according to location, clinical course and activity or behaviour patterns, and response to treatment within each IBD subtype. An ability to stratify IBD subtypes by the risk for disease progression and complications would most certainly improve overall disease outcomes through an early decision of the most appropriate treatment option available.
In addition to contributing to an improved IBD diagnosis, there is mounting evidence of a link between serum immune reactivity and specific clinical phenotypes in IBD.

In $C D$, disease extent can evolve with time from a non-stricturing, non-fistulizing, inflammatory phenotype to a more severe stricturing (fibrostenotic) or penetrating (with internal fistulae, fistulizing) phenotype (71). Numerous studies have examined the presence of different IBD-related antibodies and disease behaviour $(9,19,26,64,68,69,72-80)$. Positive association of the most of the anti-microbial, especially anti-glycan antibodies with more complicated CD phenotype and a higher frequency of Crohn's disease-related abdominal surgery has been consistently demonstrated (Table 5). It is important to emphasize that this association becomes stronger with increasing diversity (multiple antibodies) and magnitude (higher titers) of the serologic response.

Table 5. Association of serological markers with CD phenotype.

\begin{tabular}{|c|c|c|}
\hline Antibody & CD phenotype characteristics & Reference \\
\hline ASCA (ASCA+/pANCA-) & $\begin{array}{l}\text { disease located in small bowell (or ileocolonic) } \\
\text { stricturing and/or penetrating } \\
\text { higher risk for IBD-related surgical interventions } \\
\quad \text { early disease onset }\end{array}$ & $9,19,26,64,72-76,79,80$ \\
\hline pANCA (pANCA+/ASCA-) & $\begin{array}{c}\text { benign (UC-like) with colonic involvment, non-stricturing, } \\
\text { non-penetrating }\end{array}$ & $9,72,77$ \\
\hline anti-CBir1 & $\begin{array}{l}\text { disease located in small bowell, stricturing and/or penetrating } \\
\text { early disease onset }\end{array}$ & $68,69,81$ \\
\hline anti-OmpC & $\begin{array}{l}\text { disease located in small bowell, stricturing and/or penetrating } \\
\text { higher risk for IBD-related surgical interventions }\end{array}$ & $78-80$ \\
\hline anti-12 & $\begin{array}{l}\text { higher risk for stricturing phenotype } \\
\text { higher risk for IBD-related surgical interventions }\end{array}$ & 79 \\
\hline AMCA & $\begin{array}{l}\text { stricturing and/or penetrating } \\
\text { higher risk for IBD-related surgical interventions, } \\
\text { early disease onset }\end{array}$ & $19,67,78,80$ \\
\hline ACCA & $\begin{array}{l}\text { stricturing and/or penetrating } \\
\text { higher risk for IBD-related surgical interventions }\end{array}$ & $19,78,80$ \\
\hline ALCA & $\begin{array}{l}\text { stricturing and/or penetrating } \\
\text { higher risk for IBD-related surgical interventions }\end{array}$ & 78,80 \\
\hline anti-L & $\begin{array}{l}\text { stricturing and/or penetrating } \\
\text { strong association with IBD-related surgical interventions }\end{array}$ & 19,64 \\
\hline anti-C & strong association with IBD-related surgery & 64 \\
\hline \multicolumn{3}{|c|}{$\begin{array}{l}\text { ASCA - Anti-Saccharomyces cerevisiae antibodies; pANCA - anti-neutrophil cytoplasmic antibodies; Anti-Cbir1 - antibody to bacterial } \\
\text { flagellin; Anti-OmpC - antibody to outer membrane porin C; Anti-I2 - antibody to Pseudomonas fluorescens - associated sequence I2, AMCA } \\
\text { - anti-mannobioside carbohydrate antibodes; ACCA - antichitobioside carbohydrate antibodies; ALCA - antilaminaribioside carbohydrate } \\
\text { antibodies; Anti-L - anti-laminarin antibodies, Anti-C - anti-chitin antibodies. }\end{array}$} \\
\hline
\end{tabular}


Similar results were obtained in the paediatric population. Dubinsky et al. (81) evaluated associations between anti-12, anti-OmpC, anti-CBir1 and ASCA immune response and clinical phenotype in 196 paediatric CD patients. Increased frequency of internal penetrating and/or stricturing disease with increasing diversity of immune response was demonstrated, with the highest odds in patients positive for all four antibodies. Also, patients positive for $\geq 1$ antibody progressed to a complicated disease faster than those negative for all antibodies. These results were further confirmed for the same panel of antibodies in a later study performed on a 796 paediatric CD patients (82).

Data on the association of PAB with the CD phenotype are somewhat conflicting. In the Eastern European IBD cohort, antibody response to PAB was proven to be associated with complicated disease phenotype and extraintestinal manifestations. The presence of PAB was associated with perianal disease and extraintestinal manifestations such as arthritis, ocular or cutaneous manifestations. Also, the presence of PAB IgA antibodies was associated with penetrating disease behaviour (56). On the contrary, in the study of Joosens et al. (57) both PAB patterns were negatively associated with stricturing disease behaviour of CD. In the study conducted on Caucasian and Chinese IBD populations, $\mathrm{PAB}$ expression was not associated with stricturing or perforating $C D$, while in another study, the small differences in $P A B$ prevalence in $C D$ subtypes do not suggest that $P A B$ detection is useful in the discrimination of $C D$ phenotypes $(65,83)$. In a study of PAB and GAB antibodies in paediatric IBD patients, there was a lack of correlation with the clinical phenotype (66).

In contrast to CD, UC has a less heterogeneous disease behaviour but can evolve into a more aggressive phenotype with regard to a higher number of surgical interventions, moderate to severe disease activity or larger disease extent. In the study performed on 366 IBD patients, no relation of pANCA in UC patients or in CD patients was found with disease activity, duration of illness, location, disease extent, previous bowel operations or medical treatment (84). In another study, a tendency of higher prevalence of pANCA+ or pANCA+/ASCA- reactivity in severe UC compared to remission cases according to the Montreal classification was demonstrated, though this difference was not statistically significant. The pANCA-/ASCA- pattern was observed less often in active UC when compared to remission phase although with borderline significance (9).

In other UC cohorts, pANCA expression was significantly associated with a higher relapse rate, more aggressive disease course requiring early colectomy or with the treatment-resistant left-sided disease (85-87). A possible association between pAN$\mathrm{CA}$ and relative resistance to medical therapy in UC patients was also recently documented, with negative PANCA status as an independent positive predictor for response to treatment with infliximab (88).

Recent studies indicated that serological responses may identify patients with higher risk for postoperative complications in patients with UC or IBD-U. Patients who were pANCA-/ASCA+ were shown to have an increased risk for the development of fistulas after surgical intervention compared to patients who were pANCA+/ASCA-, and were also more likely to have their diagnosis changed postoperatively to CD (89). Another study confirmed preoperative ASCA-IgA seropositivity as a predictor of postoperative $C D$ diagnosis in UC and IBD-U patients (90). There is an indication that high levels of pANCA prior to colectomy is significantly associated with the development of postoperative complications in UC patients (91).

In summary, an assessment of serological markers is useful as a predictor of complicated disease behaviour in $\mathrm{CD}$ or in predicting postoperative complications in UC or IBD-U patients. The presence of multiple antibodies and the magnitude of the immunological response appear to be the strongest predictors of disease progression.

\section{Use of serologic markers in monitoring disease activity and response to drug therapy}

According to the available data, there is no use of serial measurement of IBD serological markers, including ASCA, ALCA, ACCA, anti-OmpC or pANCA in monitoring disease activity $(26,27,92)$. 
Regarding the association with response to therapy, there was no relationship between ASCA or PANCA and response to therapy in a study conducted on 279 CD patients before starting antiTNF therapy (infliximab). Although lower response rates were observed for patients with refractory intestinal disease carrying the pANCA+/ASCAcombination, this finding lacked significance $(P=$ 0.067) (93). Possible association of pANCA with relative resistance to medical therapy was further documented in a study by Sandborn et al. (87) who found an increased frequency of pANCA in treatment-resistant left-sided ulcerative colitis. The report of a negative pANCA status as an independent positive predictor for response to therapy with infliximab in UC patients supports this (88). Other studies have not found an association between ALCA, ACCA, AMCA, anti-OmpC, anti-I2 or pANCA and treatment in $C D$ (26).

\section{Other aspects of IBD serological markers}

Prevalence and diagnostic value of IBD serological markers have shown significant variation among different ethnic or geographic population. For example, in Chinese, Japanese and Iranian CD patients ASCA was shown to be less sensitive comparing to Caucasians. On the other hand, studies conducted on Tunisian, Korean and Brasilian patients yielded prevalences comparable to Caucasian CD patients The prevalence of pANCA was found to be lower in Chinese, Japanese, Korean, Thai and Romanian patients with UC but higher in Mexican-American compared to Caucasian UC patients $(26,32)$. Therefore, these data suggest that ethnic background should be considered when applying IBD serological markers in clinical practice.

Family studies indicated ASCA as potential subclinical biomarker for population in risk for $C D$, as it has been reported that this antibody is present with significantly higher frequency (20-25\%) in unaffected first-degree relatives of $C D$ patients, as compared to general healthy population (0-10\%) $(94,95)$. Furthermore, in the retrospective study, ASCA reactivity was found at a median of 38 months before clinical diagnosis in $32 \%$ of $C D$ patients (96). In contrast to ASCA, PAB seems to rarely occur in family members of patients with Crohn's disease (50).

pANCA was not proven as a marker of increased susceptibility for disease in first-degree relatives of patients with UC (26). Recent study assessed risk factors for $C D$ in multicase families and a cumulative effect of number of first-degree affected relatives, and number of positive antimicrobial antibodies (ASCA, AMCA, ALCA, ACCA, anti-OmpC, anti-CBir1, Anti-I2) was found (97).

An interesting aspect of IBD-related serologic response is their possible role in bridging the genetic susceptibility and clinical disease. Several studies investigated the association of serological markers with IBD-susceptible gene mutations $(26,98)$. In spite of some inconsistency, more studies found ASCA frequency significantly associated with greater frequency of mutant NOD2/CARD15 alleles and also the genotype-seroreactivity synergism in predicting complicated CD phenotypes $(33,59,72,99)$. In accordance with this, it is reported that association of other anti-glycan antibodies (ALCA, AMCA, ACCA and ASCA) with NOD/CARD15 mutations in a dose-effect manner is found where more mutations were associated with higher seroreactivity $(78,80)$.

\section{Conclusions}

The current diagnostic approach based upon clinical, endoscopic, histological, radiological and biochemical criteria provides a reliable diagnosis in the majority of cases of IBD over other GIT disorders that share similar clinical presentation, as well as differentiation into IBD-subtypes, CD or UC. However, there are certain cases where a significant overlap is present in the results of conventional diagnostic tests, thereby makes differentiation of these two subtypes difficult. It is this particular point in the diagnostic algorithm of IBD where serological testing has the greatest benefit. Due to their lack of sensitivity, serological markers are not advisable for use in the diagnosis of IBD but rather in differentiating $C D$ from $U C$, particularly with the use of a wide panel of antibodies. According to the growing evidence of an association between the magnitude of serological immune reactivity and specific clinical phenotypes, the most 
important clinical utility of serological markers could be in stratifying patients according to risk for aggressive disease phenotype or postoperative complications. Such a "risk score" that would integrate markers of immune response, genetic markers and clinical characteristics might enable the application of personally-tailored therapeutic

\section{References}

1. Danese S, Fiocchi C. Ulcerative Colitis. N Engl J Med 2011; 365:1713-25. http://dx.doi.org/10.1056/NEJMra1102942.

2. Podolsky DK. Inflammatory bowel disease. N Engl J Med 2002;347:417-29. http://dx.doi.org/10.1056/NEJMra020831.

3. Wilkins $T$, Jarvis $K$, Patel J. Diagnosis and management of Crohn's disease. Am Fam Physician 2011;84:1365-75.

4. Abraham C, Cho JH. Inflammatory bowel disease. $N$ Engl J Med 2009;361:2066-78. http://dx.doi.org/10.1056/NEJMra0804647.

5. Hannauer SB. Inflammatory bowel disease: Epidemiology, pathogenesis, and therapeutic opportunities. Inflamm Bowel Dis 2006;12(Suppl 1):S3-S9. http://dx.doi.org/10.1097/01. MIB.0000195385.19268.68.

6. Travis SP, Stange EF, Lemann M, Öresland T, Chowers $Y$, Forbes $A$, et al. European evidence based consensus on the diagnosis and management of Crohn's disease: current management. Gut 2006;55(Suppl 1):i16-i35. http://dx.doi.org/10.1136/ gut.2005.081950b.

7. Stange EF, Travis SPL, Vermiere S, Beglinger $C$, Kupcinkas $L$, Geboes $K$, et al. European evidence based consensus on the diagnosis and management of Crohn's disease: definitions and diagnosis. Gut 2006;55(Suppl 1):i1-i15. http://dx.doi. org/10.1136/gut.2005.081950a.

8. Carter MJ, Lobo AJ, Travis SPL. Guidelines for the management of inflammatory bowel disease in adults. Gut 2004;53(Suppl 5):v1-v16. http://dx.doi.org/10.1136/gut.2004.043372.

9. Mokrowiecka A, Kumor A, Jakubczyk E, Pietruczuk M, Malecka-Panas $E$. The application of Montreal classification in different clinical and serological IBD subtypes. Hepatogastroenterology 2010;57:787-93.

10. Arai R. Serologic markers: impact on early diagnosis and disease stratification in inflammatory bowel disease. Postgrad Med 2010;122:177-85. http://dx.doi.org/10.3810/ pgm.2010.07.2184.

11. Tsianos EV, Katsanos K. Do we really understand what immunological disturbances in inflammatory bowel disease mean? World J Gastroenterol 2009;15:521-55. http://dx.doi. org/10.3748/wjg.15.521.

12. Hart AL, Ng SC, Mann E, Al-Hassi HO, Bernardo D, Knight SC. Homing of immune cells: Role in homeostasis and intestinal inflammation. Inflamm Bowel Dis 2010;16:1969-77. http:// dx.doi.org/10.1002/ibd.21304.

13. Mudter J. Innate and adaptive immunity in inflammatory bowel disease. World J Gastroenterol 2011;17:3178-83.

14. Danese S, Fiocchi C. Etiopathogenesis of inflammatory bowel diseases. World J Gastroenterol 2006;12:4807-12. strategies and better surveillance of patients at risk. At the current time, there is insufficient evidence of usefulness of serological markers in monitoring the treatment of IBD patients.

\section{Potential conflict of interest}

None declared.
15. Homsak E, Micetic-Turk D, Bozic B. Autoantibodies pANCA, $G A B$ and $P A B$ in inflammatory bowel disease: prevalence, characteristics and diagnostic value. Wien Klin Wochenschr 2010;122(Suppl 2):19-25. http://dx.doi.org/10.1007/s00508010-1344-y.

16. Mendoza JL, Abreu MT. Biological markers in inflammatory bowel disease: Practical consideration for clinicians. Gastroenterol Clin Biol 2009;33(Suppl 3):S158-73. http://dx.doi. org/10.1016/S0399-8320(09)73151-3.

17. Reumaux D, Sendid B, Poulain D, Duthilleul P, Dewit O, Colombel JF. Serological markers in inflammatory bowel diseases. Best Pract Res Clin Gastroenterol 2003;17:19-35. http:// dx.doi.org/10.1053/bega.2002.0347.

18. Dotan $N$, Altstock RT, Schwarz $M$, Dukler A. Anti-glycan antibodies as biomarkers for diagnosis and prognosis. Lupus 2006;15:442-50. http://dx.doi. org/10.1191/0961203306/u2331oa.

19. Rieder F, Schleder S, Wolf A, Dirmeier A, Strauch U, Obermeier F, et al. Serum Anti-glycan antibodies predict complicated Crohn's disease behavior: a cohort study. Inflamm Bowel Dis 2010;16:1367-75.

20. Sendid B, Colombel JF, Jacquinot PM, Faille C, Fruit J, Cortot $A$, et al. Specific antibody response to oligomannosidic epitopes in Crohn's disease. Clin Diagn Lab Immunol 1996;3:219 26.

21. Ukabam SO, Clamp JR, Cooper BT. Abnormal small intestinal permeability to sugars in patients with Crohn's disease of the terminal ileum and colon. Digestion 1983;27:70-4. http:// dx.doi.org/10.1159/000198932.

22. McKenzie H, Parrat D, Main J, Pennington CR. Antigenic heterogeneity of strains of Saccharomyces cerevisiae and Candida albicans recognised by serum antibodies from patients with Crohn's disease. FEMS Microbiol Immunol 1992;89:219 24. http://dx.doi.org/10.1111/j.1574-6968.1992.tb04997.x.

23. Standaert-Vitse A, Jouault $T$, Vandewalle P, Mille $C$, Seddik $M$, Sendid $B$, et al. Candida albicans is an immunogen for antiSaccharomyces cerevisiae antibody markers of Crohn's disease. Gastroenterology 2006;130:1764-75. http://dx.doi. org/10.1053/j.gastro.2006.02.009.

24. Wayne $L G$, Hollander $D$, Anderson B, Sramek HA, Vadheim CM, Rotter Jl. Immunoglobulin A (IgA) and IgG serum antibodies to mycobacterial antigens in Crohn's disease patients and their relatives. J Clin Microbiol 1992;30:2013-8.

25. Nakamura RM, Matsutani M, Barry M. Advances in clinical laboratory tests for inflammatory bowel disease. Clin Chim Acta 2003;335:9-20. http://dx.doi.org/10.1016/S0009-8981(03)00286-9. 
26. Prideaux L, De Cruz P, Ng SC, Kamm MA. Serological antibodies in inflammatory bowel disease: a systematic review. Inflamm Bowel Dis 2012;18:1340-55. http://dx.doi.org/10.1002/ ibd.21903.

27. Bossuyt $X$. Serologic markers in inflammatory bowel disease. Clin Chem 2006;52:171-81. http://dx.doi.org/10.1373/ clinchem.2005.058560.

28. Sandborn WJ. Serologic markers in inflammatory bowel disease: state of the art. Rev Gastroenterol Disord 2004;4:167-74.

29. Desplat-Jego S, Johanet C, Escande A, Goetz J, Fabien N, Olsson $N$, et al. Update on anti-Saccharomyces cerevisiae antibodies, anti-nuclear associated anti-neutrophil antibodies and antibodies to exocrine pancreas detected by indirect immunofluorescence as biomarkers in chronic inflammatory bowel diseases: results of a multicenter study. World J Gastroenterol 2007;13:2312-8.

30. Mokrowiecka A, Daniel P, Slomka M, Majak P, Panas EM. Clinical utility of serological markers in inflammatory bowel disease. Hepatogastroenterology 2009;56:162-6.

31. Dotan I, Fishman S, Dgani Y, Schwartz M, Karban A, Lerner $A$, et al. Antibodies against laminaribioside and chitobioside are novel serologic markers in Crohn's disease. Gastroenterology 2006;131:366-78. http://dx.doi.org/10.1053/j. gastro.2006.04.030.

32. Mizoguchi E. New serological biomarkers of inflammatory bowel disease. World J Gastroenterol 2008;14:5115-24. http://dx.doi.org/10.3748/wjg.14.5115.

33. Dotan I. New serologic markers for inflammatory bowel disease diagnosis. Dig Dis 2010;28:418-23. http://dx.doi. org/10.1159/000320396.

34. Seow CH, Stempak JM, Xu W, Stat P, Lan H, Griffiths AM, et al. Novel anti-glycan antibodies related to inflammatory bowel disease diagnosis and phenotype. Am J Gastroenterol 2009;104:1426-34. http://dx.doi.org/10.1038/ajg.2009.79.

35. Cohavy O, Bruckner D, Gordon LK, Misra R, Wei B, Eggena ME, et al. Colonic bacteria express an ulcerative colitis pANCA-related protein epitope. Infect Immun 2000;68:1542-8. http:// dx.doi.org/10.1128/IAl.68.3.1542-1548.2000.

36. Landers CJ, Cohavy O, Misra R, Yang H, Lin YC, Braun J, Targan SR. Selected loss of tolerance evidenced by Crohn's disease-associated immune responses to auto- and microbial antigens. Gastroenterology 2002;123:689-99. http://dx.doi. org/10.1053/gast.2002.35379.

37. Joossens S, Colombel JF, Landers C, Poulain D, Geboes K, Bossuyt $X$, et al. Anti-outer membrane of porin C and anti-12 antibodies in indeterminate colitis. Gut 2006;55:1667-9. http:// dx.doi.org/10.1136/gut.2005.089623.

38. Sutton CL, Kim J, Yamane A, Dalwadi H, Wei B, Landers C, et al. Identification of a novel bacterial sequence associated with Crohn's disease. Gastroenterology 2000;119:23-31. http://dx.doi.org/10.1053/gast.2000.8519.

39. Wei B, Huang T, Dalwadi H, Sutton CL, Bruckner D, Braun J. Pseudomonas fluorescens encodes the Crohn's disease-associated 12 sequence and T-cell superantigen. Infect Immun 2002;70:6567-75. http://dx.doi.org/10.1128/IAl.70.12.65676575.2002.

40. Lodes MJ, Cong Y, Elson CO, Mohamath R, Landers CJ, Targan $S R$, et al. Bacterial flagellin is a dominant antigen in Crohn's disease. J Clin Invest 2004;113:1296-306.
41. Savige J, Dimech W, Fritzler M, Goeken J, Hagen C, Jennette $C$, et al. Addendum to the International Consensus Statement on Testing and Reporting of Antineutrophil Cytoplasmic Antibodies. Quality Control Guidelines, Comments, and Recommendations for Testing in Other Autoimmune Diseases. Am J Clin Pathol 2003;120:312-8. http://dx.doi.org/10.1309/WAEPADWOK4LPUHFN.

42. Kallenberg CGM, Heeringa P, Stegeman CA. Mechanisms of disease: pathogenesis and treatment of ANCA-associated vasculitides. Nat Clin Pract Rheumatol 2006;2:661-70. http:// dx.doi.org/10.1038/ncprheum0355.

43. Editorial. Rational use of ANCA in the diagnosis of vasculitis. Rheumatology 2002;41:481-3. http://dx.doi.org/10.1093/ rheumatology/41.5.481.

44. Saxon A, Shanahan F, Landers C, Ganz T, Targan S. A distinct subset of antineutrophil cytoplasmic antibodies is associated with inflammatory bowel disease. J Allergy Clin Immunol 1990;86:202-10. http://dx.doi.org/10.1016/S0091-6749(05)80067-3.

45. Rump JA, Schölmerich J, Gross V, Roth $M$, Helfesrieder $R$, Rautmann $A$, et al. A new type of perinuclear anti-neutrophil cytoplasmic antibody ( $p$-ANCA) in active ulcerative colitis but not in Crohn's disease. Immunobiology 1990;181:406-13. http://dx.doi.org/10.1016/S0171-2985(11)80509-7.

46. Billing P, Tahir S, Cifin B, Gagne G, Cobb L, Targan SR, et al. Nuclear localization of the antigen detected by ulcerative colitis-associated perinuclear antineutrophil cytoplasmic antibodies. Am J Pathol 1995; 147:979-87.

47. Vidrich A, Lee J, James E, Cobb L, Targan S. Segregation of pANCA antigenic recognition by DNAse treatment of neutrophils: ulcerative colitis, type I autoimmune hepatitis, and primary sclerosing cholangitis. J Clin Immunol 1995;15:293-9. http://dx.doi.org/10.1007/BF01541319.

48. Teegen B, Niemann S, Probst C, Schlumberger W, Stöcker W, Komorowski L. DNA-bound lactoferrin is the major target for antineutrophil perinuclear cytoplasmic antibodies in ulcerative colitis. Contemporary Challenges in Autoimmunity: Ann N Y Acad Sci 2009;1173:161-5. http://dx.doi.org/10.1111/ j.1749-6632.2009.04752.x

49. Stöcker W, Otte M, Ulrich S, Normann D, Finkbeiner H, Stöcker $K$, et al. Autoimmunity to pancreatic juice in Crohn's disease. Results of an autoantibody screening in patients with chronic inflammatory bowel disease. Scand J Gastroenterol 1987;22(Suppl 139):41-52. http://dx.doi. org/10.3109/00365528709089774.

50. Seibold F, Mörk H, Tanza S, Müller A, Holzhüter C, Weber $P_{1}$ Scheurlen M. Pancreatic autoantibodies in Crohn's disease: a family study. Gut 1997;40:481-4.

51. Roggenbuck $D$, Hausdorf $D$, Martinez-Gamboa I, Reinhold $D$, Büttner T, Jungblut PR, et al. Identification of GP2, the major zymogen granule membrane glycoprotein, as the autoantigen of pancreatic antibodies in Crohn's disease. Gut 2009;58:1620-8. http://dx.doi.org/10.1136/gut.2008.162495.

52. Terahara K, Yoshida M, Igarashi S, Nochi T, Soares Pontes G, Hase $K$, et al. Comprehensive gene expression profiling of Peyer's patch $M$ cells, villous $M$-like cells, and intestinal epithelial cells. J Immunol 2008;180:7840-6.

53. Ohno H, Hase K. Glycoprotein 2 (GP2) grabbing the FimH+ bacteria into $M$ cells for mucosal immunity. Gut Microbes 2010;1:407-10. http://dx.doi.org/10.4161/gmic.1.6.14078. 
54. Corr SC, Gahan CC, Hill C. M-cells: origin, morphology and role in mucosal immunity and microbial pathogenesis. FEMS Immunol Med Microbiol 2008;52:2-12. http://dx.doi. org/10.1111/j.1574-695X.2007.00359.x.

55. Hibi T, Ohara M, Kobayashi K, Brown WR, Toda K, Takaishi $H$, et al. Enzyme linked immunosorbent assay (ELISA) and immunoprecipitation studies on anti-goblet cell antibody using a mucin producing cell line in patients with inflammatory bowel disease. Gut 1994;35:224-30. http://dx.doi. org/10.1136/gut.35.2.224.

56. Lakatos L, Altorjay I, Szamosi T, Palatka K, Vitalis Z, Tumpek $J$, et al. Pancreatic autoantibodies are associated with reactivity to microbial antibodies, penetrating disease behavior, perianal disease, and extraintestinal manifestations, but not with NOD2/CARD15 or TLR4 genotype in a Hungarian IBD cohort. Inflamm Bowel Dis 2009;15:365-74. http://dx.doi. org/10.1002/ibd.20778.

57. Joossens $S$, Vermeire $S$, Van Steen $K$, Godefridis $G$, Claessens $G$, Pierik $M$, et al. Pancreatic autoantibodies in inflammatory bowel disease. Inflamm Bowel Dis 2004;10:771-7. http:// dx.doi.org/10.1097/00054725-200411000-00012.

58. Riis L, Vind I, Vermeire S, Wolters F, Katsanos K, Politi $P$, et al. The prevalence of genetic and serologic markers in an unselected European population-based cohort of IBD patients. Inflamm Bowel Dis 2007;13:24-32. http://dx.doi.org/10.1002/ ibd.20047.

59. Grzybowska-Chlebowczyk U, Wos H, Sieron AL, Wiecek S, Augusciak-Duma A, Koryciak-Komarska H, Kasznia-Kocot J. Serologic investigation in children with inflammatory bowel disease and food allergy. Mediators Inflamm 2009; 512695. http://dx.doi.org/10.1155/2009/512695.

60. Basta Z, Csi I, Szabo G, Szegedi G. Seroreactovity against Saccharomyces cerevisiae in patients with Crohn's disease and celiac disease. World J Gastroenterol 2003;9:2380-12.

61. Granito A, Zauli D, Muratori P, Muratori L, Grassi A, Bortolotti $R$, et al. Anti-Saccharomyces cerevisiae and perinuclear anti-neutrophil cytoplasmic antibodies in coeliac disease before and after gluten-free diet. Aliment Pharmacol Ther 2005;21:881-7. http://dx.doi.org/10.1111/j.1365-2036 .2005.02417.x.

62. Carvalho RS, Abadom V, Dilworth HP, Thompson R, OlivaHemker M, Cuffari C. Indeterminate colitis: a significant subgroup of pediatric IBD. Inflamm Bowel Dis 2006;12:258-62. http://dx.doi.org/10.1097/01.MIB.0000215093.62245.69.

63. Joossens $S$, Reinisch $W$, Vermiere $S$, Sendid B, Poulain D, Peeters $M$, et al. The value of serologic markers in indeterminate colitis: a prospective follow-up study. Gastroenterology 2002;122:1242-7. http://dx.doi.org/10.1053/gast. 2002.32980.

64. Rieder F, Schleder S, Wolf A, Dirmeier A, Strauch U, Obermeier $F$, et al. Association of the novel serologic anti-glycan antibodies anti-laminarin and anti-chitin with complicated Crohn's disease behavior. Inflamm Bowel Dis 2010;16:263-74.

65. Lawrance IC, Hall A, Leong R, Pearce C, Murray K. A Comparative study of goblet cell and pancreatic exocine autoantibodies combined with ASCA and PANCA in Chinese and Caucasian patients with IBD. Inflamm Bowel Dis 2005;11:890-7. http://dx.doi.org/10.1097/01.MIB.0000182872.76434.8c.

66. Kovacs M, Lakatos PL, Papp M, Jacobsen S, Nemes E, PolgarM, et al. Pancreatic autoantibodies and autoantibodies against goblet cells in pediatric patients with inflammatory bowel disease (IBD). J Pediatr Gastroenterol Nutr 2012;55:429-35. http://dx.doi.org/10.1097/MPG.0b013e318256b516.
67. Simondi $D$, Mengozzi $G$, Betteto $S$, Bonardi R, Ghignone RP, Fagoonee $S$, et al. Antiglycan antibodies as serological markers in the differential diagnosis of inflammatory bowel disease. Inflamm Bowel Dis 2008;14:645-51. http://dx.doi. org/10.1002/ibd.20368.

68. Targan SR, Landers CJ, Yang H, Lodes MJ, Cong Y, Papadakis $K A$, et al. Antibodies to CBir1 flagellin define a unique response that is associated independently with complicated Crohn's disease. Gastroenterology 2005;128:2020-8. http://dx.doi. org/10.1053/j.gastro.2005.03.046.

69. Markowitz J, Kugathasan S, Dubinsky M, Mei L, Crandall W, LeLeiko $N$, et al. Age of diagnosis influences serologic responses in children with Crohn's disease: a possible clue to etiology? Inflamm Bowel Dis 2009;15:714-9. http://dx.doi. org/10.1002/ibd.20831.

70. Stöcker W, Otte M, Ulrich S, Normann D, Finkbeiner H, Stöcker $K$, et al. Autoimmunity to Pancreatic Juice in Crohn's Disease Results of an Autoantibody Screening in Patients with Chronic Inflamm Bowel Dis. Scand J Gastroenterol 1987;22:41-52. http://dx.doi.org/10.3109/00365528709089774.

71. Satsangi J, Silverberg MS, Vermeire S, Colombel JF. Montre al classification of inflammatory bowel disease: controversies, consensus, and implications. Gut 2006;55:749-53. http:// dx.doi.org/10.1136/gut.2005.082909.

72. Schoepfer AM, Schaffer T, Mueller S, Flogerzi B, Vassella E, Seibold-Schmid B, et al. Phenotypic associations of Crohn's disease with antibodies to flagellins A4-Fla2 and Fla-X, ASCA, $p$-ANCA, PAB, and NOD2 mutations in a Swiss cohort. Inflamm Bowel Dis 2009;15:1358-67. http://dx.doi.org/10.1002/ ibd.20892.

73. Quinton JF, Sendid B, Reumaux D, Duthilleul P, Cortot A, Grandbastien B, et al. Anti-Saccharomyces cerevisiae mannan antibodies combined with antineutrophil cytoplasmic autoantibodies in inflammatory bowel disease: prevalence and diagnostic role. Gut 1998;42:788-91. http://dx.doi.org/10.1136/ gut.42.6.788.

74. Koutroubakis IE, Petinaki E, Mouzas IA, Vlachonikolis IG, Anagnostopoulou E, Castanas E, et al. Anti-saccharomyces cerevisiae mannan antibodies and antineutrophil cytoplasmic autoantibodies in Greek patients with inflammatory bowel disease. Am J Gastroenterology 2001;96:449-54.

75. Amre DK, Lu SE, Costea F, Seidman EG. Utility of serological markers in predicting the early occurrence of complications and surgery in pediatric Crohn's disease patients. Am J Gastroenterol 2006;101:645-52. http://dx.doi.org/10.1111/ j.1572-0241.2006.00468.x.

76. Forcione DG, Rosen MJ, Kisiel JB, Sands BE. Anti-Saccharomyces cerevisiae antibody (ASCA) positivity is associated with increased risk for early surgery in Crohn's disease. Gut 2004;53:1117-22. http://dx.doi.org/10.1136/ gut.2003.030734.

77. Vasiliauskas EA, Kam LY, Karp LC, Gaiennie J, Yang H, Targan SR. Marker antibody expression stratifies Crohn's disease into immunologically homogeneous subgroups with distinct clinical characteristics. Gut 2000;47:487-96. http://dx.doi. org/10.1136/gut.47.4.487.

78. Papp M, Altorjay I, Dotan N, Palatka K, Foldi I, Tumpek J, et al. New serological markers for inflammatory bowel disease are associated with earlier age at onset, complicated disease behavior, risk for surgery, and NOD2/CARD15 genotype in a Hungarian IBD cohort. Am J Gastroenterol 2008;103:665-81. http://dx.doi.org/10.1111/j.1572-0241.2007.01652.x. 
79. Mow WS, Vasiliauskas EA, Lin YC, Fleshner PR, Papadakis KA, Taylor KD, et al. Association of antibody responses to microbial antigens and complications of small bowel Crohn's disease. Gastroenterology 2004;126:414-24. http://dx.doi. org/10.1053/j.gastro.2003.11.015.

80. Ferrante $M$, Henckaerts $L$, Joossens $M$, Pierik $M$, Joossens $S$, Dotan $N$, et al. New serological markers in inflammatory bowel disease are associated with complicated disease behaviour. Gut 2007;56:1394-403. http://dx.doi.org/10.1136/ gut.2006.108043.

81. Dubinsky MC, Lin YC, Dutridge D, Picornell Y, Landers CJ, Farrior $S$, et al. Serum immune responses predict rapid disease progression among children with Crohn's disease: immune responses predict disease progression. Am J Gastroenterol 2006;101:360-7. http://dx.doi.org/10.1111/j.1572-0241 .2006.00456.x.

82. Dubinsky MC, Kugathasan S, Mei L, Picornell Y, Nebel J, Wrobel $I$, et al. Increased immune reactivity predicts aggressive complicating Crohn's disease in children. Clin Gastroenterol Hepatol 2008;6:1105-11. http://dx.doi.org/10.1016/j. cgh.2008.04.032.

83. Klebl FH, Bataille F, Huy C, Hofstädter F, Schölmerich J, Rogler $G$. Association of antibodies to exocrine pancreas with subtypes of Crohn's disease. Eur J Gastroenterol Hepatol 2005;17:73-7. http://dx.doi.org/10.1097/00042737200501000-00015.

84. Oudkerk Pool $M$, Ellerbroek PM, Ridwan BU, Goldschmeding $R$, von Blomberg BM, Pena AS, et al. Serum antineutrophil cytoplasmic autoantibodies in inflammatory bowel disease are mainly associated with ulcerative colitis. A correlation study between perinuclear antineutrophil cytoplasmic autoantibodies and clinical parameters, medical, and surgical treatment. Gut 1993;34:46-50. http://dx.doi.org/10.1136/ gut.34.1.46.

85. Høie O, Aamodt G, Vermeire S, Bernklev T, Odes S, Wolters $F L$, et al. Serological markers are associated with disease course in ulcerative colitis. A study in an unselected population-based cohort followed for 10 years. Journal of Crohn's and Colitis 2008;2:114-22. http://dx.doi.org/10.1016/j. crohns.2007.10.001.

86. Vecchi M, Bianchi MB, Sinico RA, Radice A, Meucci G, Torgano $G$, et al. Antibodies to neutrophil cytoplasm in Italian patients with ulcerative colitis: sensitivity, specificity and recognition of putative antigens. Digestion 1994;55:34-9. http:// dx.doi.org/10.1159/000201120.

87. Sandborn WJ, Landers CJ, William BS, Tremaine J, Targan SR. Association of antineutrophil cytoplasmic antibodies with resistance to treatment of left-sided ulcerative colitis: results of a pilot study. Mayo Clin Proc 1996;71:431-6. http://dx.doi.org/10.4065/71.5.431.

88. Jürgens $M$, Laubender RP, Hartl $F$, Weidinger $M$, Seiderer J, Wagner J, et al. Disease activity, ANCA, and IL23R genotype status determine early response to Infliximab in patients with ulcerative colitis. Am J Gastroenterol 2010;105:1811-9. http:// dx.doi.org/10.1038/ajg.2010.95.
89. Dendrinos KG, Becker JM, Stucch AF, Saubermann LJ, LaMorte W, Farraye FA. Anti-Saccharomyces cerevisiae antibodies are associated with the development of postoperative fistulas following illeal pouch-anal anastomosis. J Ga strointest Surg 2006;10:1060-4. http://dx.doi.org/10.1016/j. gassur.2006.02.004.

90. Melmed GY, Fleshner PR, Bardakcioglu O, Ippoliti A, Vasiliauskas EA, Papadakis KA, et al. Family history and serology predict Crohn's disease after ileal pouch-anal anastomosis for ulcerative colitis. Dis Colon Rectum 2008;51:100-8. http:// dx.doi.org/10.1007/s10350-007-9158-3.

91. Fleshner PR, Vasiliauskas EA, Kam LY, Fleshner NE, Gaiennie J, Abreu-Martin MT, Targan SR. High level perinuclear antineutrophil cytoplasmic antibody (pANCA) in ulcerative colitis patients before colectomy predicts the development of chronic pouchitis after ileal pouch-anal anastomosis. Gut 2001;49:671-7. http://dx.doi.org/10.1136/gut.49.5.671.

92. Reumaux D, Colombel JF, Masy E, Duclos B, Heresbach D, Belakhe J, et al. Anti-neutrophil cytoplasmic auto-antibodies (ANCA) in ulcerative colitis (UC): no relationship with disease activity. Inflamm Bowel Dis 2000;6:270-4.

93. Esters N, Vermeire S, Joossens S, Noman M, Louis E, Belaiche $J$, at al. Serological markers for prediction of response to anti-tumor necrosis factor treatment in Crohn's disease. Am J Gastroenterol 2002;97:1458-62. http://dx.doi.org/10.1111/ j.1572-0241.2002.05689.x.

94. Sendid B, Quinton JF, Charrier G, Goulet O, Cortot A, Grandbastien $B$, et al. Anti-Saccharomyces cerevisiae mannan antibodies in familial Crohn's disease. Am J Gastroenterol 1998;93:1306-10. http://dx.doi.org/10.1111/j.1572-0241 .1998.00415.x.

95. Seibold F, Stich O, Hufnagl R, Kamil S, Scheurlen M. Anti-Saccharomyces cerevisiae antibodies in inflammatory bowel disease: a family study. Scand J Gastroenterol 2001;36:196201. http://dx.doi.org/10.1080/003655201750065960.

96. Israeli E, Grotto I, Gilburd B, Balicer RD, Goldin E, Wiik A, Shoenfeld Y. Anti-Saccharomyces cerevisiae and antineutrophil cytoplasmic antibodies as predictors of inflammatory bowel disease. Gut 2005;54:1232-6. http://dx.doi.org/10.1136/ gut.2004.060228.

97. Joossens M, Van Steen K, Branche J, Sendid B, Rutgeers P, Vasseur $F$, et al. Familial aggregation and antimicrobial response dose-dependently affect the risk for Crohn's disease. Inflamm Bowel Dis 2010;16:58-67.

98. Li X, Conklin L, Alex P. New serological biomarkers of inflammatory bowel disease. World J Gastroenterology 2008;14:5115-24. http://dx.doi.org/10.3748/wjg.14.5115.

99. Dassopoulos T, Frangakis C, Cruz-Correa M, Talor MV, Burek $C L$, Datta L, Nouvet F. Antibodies to Saccharomyces cerevisiae in Crohn's disease: Higher titers are associated with a greater frequency of mutant NOD2/CARD15 alleles and with a higher probability of complicated disease. Inflamm Bowel Dis 2007;13:143-51. http://dx.doi.org/10.1002/ibd.20031. 